\title{
Anabases
}

ANABASES Traditions et réceptions de l'Antiquité

19 | 2014

Varia

\section{Bruce GIBSON \& Thomas HARRISON (ed.), Polybius and his world, Essays in Memory of F.W. Walbank}

\section{Germaine Aujac}

\section{OpenEdition}

\section{Journals}

Édition électronique

URL : http://journals.openedition.org/anabases/4734

DOI : $10.4000 /$ anabases.4734

ISSN : 2256-9421

\section{Éditeur}

E.R.A.S.M.E.

\section{Édition imprimée}

Date de publication : 1 avril 2014

Pagination : 345-347

ISSN : 1774-4296

\section{Référence électronique}

Germaine Aujac, «Bruce giBson \& Thomas HARRIson (ed.), Polybius and his world, Essays in Memory of F.W. Walbank», Anabases [En ligne], 19 | 2014, mis en ligne le 01 avril 2014, consulté le 22 septembre 2020. URL : http://journals.openedition.org/anabases/4734; DOI : https://doi.org/10.4000/anabases. 4734

Ce document a été généré automatiquement le 22 septembre 2020.

(c) Anabases 


\title{
Bruce GIBSON \& Thomas HARRISON (ed.), Polybius and his world, Essays in Memory of F.W. Walbank
}

\author{
Germaine Aujac
}

\section{RÉFÉRENCE}

Bruce GIBSON \& Thomas HARRISON (ed.), Polybius and his world, Essays in Memory of F.W.

Walbank, Oxford, Oxford University Press, 2013, 416 p.

85 livres / ISBN 978-0-19-960840-9

1 En juillet 2007, une conférence réunissait à Liverpool des Universitaires spécialistes de Polybe pour célébrer le cinquantième anniversaire de la parution du premier volume $\mathrm{du}$ fameux Commentaire Historique. Son auteur, F.W. Walbank, qui n'avait pu être présent, adressait un vidéo-message de bienvenue à ses collègues, rappelant au passage qu'il connut l'historien de Rome dès l'âge de 18 ans grâce à son maître, Ned Goddard. Le 23 octobre 2008, Frank Walbank décédait, et les Actes de la conférence tenue l'année précédente allaient devenir un vibrant hommage à la mémoire de ce grand érudit.

2 En Introduction, les éditeurs de ce volume évoquaient l'homme et le savant. Très engagé dans le présent et la vie politique, F.W. Walbank n'en produisit pas moins, en dépit de bien des difficultés familiales, une œuvre considérable (sa bibliographie occupe plus de quatre pages en fin de volume). À la thèse sur Aratos of Sicyon (1933) succédèrent Philip V of Macedon (1940), puis The Decline of the Roman Empire in the West (1946), où les références à l'actualité sont légion. J. Henderson, utilisant les Mémoires de FWW qui s'arrêtaient en 1946 (date de sa nomination à la chaire de Latin à Liverpool), évoque ses hésitations avant le choix définitif d'un travail qui allait l'occuper durant tant d'années, et puis ses démêlés avec les éditeurs pour la publication d'un Commentaire prévu d'abord pour n'occuper que deux livres. En fin de volume, le touchant témoignage de Mitzy Walbank, sa fille cadette, dresse le portrait d'un père 
complètement absorbé par son travail, pour qui Polybe devint un refuge aux jours de deuil et de solitude; pour les enfants, Polybe resta longtemps l'ennemi avec lequel il fallait bien vivre.

3 C'est pourtant Polybe et son temps qui constituent le sujet essentiel de ces Actes, même si FWW y occupe une très large place. Pour J. Marincola, Polybe, reprochant à Phylarque ses effets dramatiques, soutient, à l'inverse d'Aristote, la supériorité de l'histoire, plus proche de la vie réelle, sur la tragédie. A. Meadows considère pour sa part que Polybe ne commence véritablement son Histoire qu'en 220 av. J.-C., à la $140^{\mathrm{e}}$ Olympiade ; il prend alors la suite des Mémoires d'Aratos dont il s'était servi jusque-là. Pour J. Briscoe, Tite Live, qui s'inspire de Polybe pour les années 201-197 av. J.-C., s'est plusieurs fois mépris sur le sens à donner au texte de sa principale source. D'après $\mathrm{H}$. Beck, les livres I et II sur les guerres Puniques auraient été fortement influencés par les traités de Fabius Pictor et surtout de Philinus. Quant à la crise Mamertine, si Polybe reste assez vague dans son récit, ce serait, d'après $\mathrm{Cr}$. Champion, afin que ses lecteurs, grecs ou romains, puissent interpréter à leur gré la décision de Rome de débarquer en Sicile en 264. À propos de la guerre des Mercenaires, qui annonçait le déclin de Carthage, B. Gibson rappelle le rôle des mercenaires dans l'Anabase de Xénophon. Quant à B. McGing, il souligne avec humour l'intérêt de Polybe pour la jeunesse, et pour les jeunes dirigeants, dont Philippe $\mathrm{V}$ qui, après des débuts si prometteurs, se laissa abuser par de mauvais conseillers et finit en cruel tyran. Évoquant de son côté l'article de FWW consacré aux dernières années de Philippe $\mathrm{V}$, et à son déplorable changement d'attitude en 215-213 av. J.-C., B. Dreyer ne manque pas d'ajouter que Persée suivit son père dans sa folie.

4 J. Thornton insiste sur le fait que les relations diplomatiques entre Rome et la Grèce (le Grec Polybe vint à Rome comme otage, après la défaite de la ligue achéenne) ont dû forcément influencer l'historien dans son interprétation du passé. Quant à A. Erskine, "reconsidérant » le livre VI, il suggère que son but essentiel serait de montrer Rome comme un modèle d'ordre et d'efficacité, et la société romaine comme uniquement préoccupée du bien public, tout y étant subordonné à l'État. C'est encore au livre VI que fait référence R. Seager, dénonçant Polybius' Distortions of the Roman Constitution; certaines omissions délibérées de Polybe voilent le fait que Rome fonctionne réellement comme une oligarchie, seulement contrôlée par le Sénat.

E.S. Gwen établit un parallélisme assez inattendu entre les destinées et les objectifs de Polybe et de Josèphe : les deux historiens insistent sur le rôle de la Fortune (Tychè) dans le cours des événements et ne craignent pas, surtout Josèphe, de décrire les atrocités commises par les Romains. C. Müller voit dans la brève histoire des Béotiens selon Polybe (Histoire, 20, 4-7) l'expression d'un topos littéraire. H.U. Wiemer, qui s'intéresse à l'historiographie dans le monde hellénistique, tente de reconstituer l'œuvre de Zénon de Rhodes; il se sert pour cela des opinions de Polybe sur le Rhodien, et surtout des emprunts supposés de Diodore de Sicile à propos de l'archéologie de Rhodes ou de la glorieuse résistance de cette ville au siège de Démétrius; Polybe aurait eu raison de reprocher à Zénon sa partialité à l'égard de sa patrie. Traitant d'un sujet apparemment plus léger, M. Sommer évoque, en prenant pour exemple les relations entre Polybe et le jeune Scipion Émilien, la quête générale d'amitié dans la Rome du second siècle av. J.C. ; mais il insiste sur la différence entre la philia grecque et l'amicitia romaine ; en fait Polybe n'est qu'un «client» de Scipion, pas un ami; et la république romaine dont il présente si favorablement la constitution n'existerait que dans son esprit. J.K. Davies 
collecte une foule de renseignements, tirés de l'Histoire de Polybe, concernant l'économie méditerranéenne (produits de la terre, peuplement, mouvements de population), ou encore les divers types de comportement économique (piraterie, fiscalité, modes de production). Pour J. Crawley Quinn, Imagining the Imperial Mediterranean, Polybe présente «les Romains et les Grecs comme participants d'une seule communauté historique, construisant non une nation mais un empire» (p. 339) ; le procédé qui consiste à décrire les événements année par année renforce une conception de simultanéité à travers l'espace, et donc de synchronisme entre l'est et l'ouest.

Une abondante bibliographie, un index locorum, un index général, complètent ce fort beau volume qui nous révèle beaucoup d'aspects mal connus aussi bien de l'historien de Rome que de son illustre commentateur.

\section{AUTEURS}

\section{GERMAINE AUJAC}

Université de Toulouse (UTM)

aujac.germaine@wanadoo.fr 